\title{
Economic Cost of Malaria Treatment under the Health Insurance Scheme in the Savelugu-Nanton District of Ghana
}

\author{
Hamza Bukari Zakaria \\ Institute for Continuing Education and Interdisciplinary Research (ICEIR) \\ University for Development Studies \\ Tamale, Ghana \\ Email: hbukari@uds.edu.gh \\ and \\ Felix Ankomah Asante \\ Institute for Statistical, Social and Economic Research (ISSER) \\ University of Ghana, Legon \\ Email:fasante@ug.edu.gh \\ DOI/http://dx.doi.org/10.4324/gjds.v10i1\&2.1
}

\begin{abstract}
The paper discusses the findings of a survey which explored the implications of access to health care by examining costs incurred by health insurance card holders in the Savelugu-Nanton District. Treatment for malaria, a disease that causes morbidity and mortality in Sub-Sahara Africa, based on the Cost of Illness Approach (CIA) was used to compute the cost of health care. An analysis of the survey data showed that health seeking behaviour was consistent with economic theorists who argue that cost-benefit considerations influence the behaviour and actions of individuals who benefit from health insurance. While the dominant motive for obtaining health insurance was to have access to affordable health care, solidarity appeared to be low among members of the District Mutual Health Insurance Scheme. The cost of malaria treatment borne by patients under health insurance was valued at GH\& 71.3 or US\$46.20 (2009 prices). While indirect costs were disproportionately greater than direct costs, the study affirmed that health insurance generally insulate subscribers from monetary payments which in itself increases both attendance and utilisation of health services even though the implication of this phenomenon on time loss and productivity appear to be rather enormous.
\end{abstract}

Key Words: Health Insurance Scheme, Cost of Illness, Human Capital, Malaria, User fees. 


\section{Introduction}

Since independence in 1957, various governments of Ghana have introduced policies aimed at improving the health and general wellbeing of Ghanaians. The seven-year and five - year development plans of the early independence era, as well as socio-economic policies in recent decades such as the poverty reduction strategy papers (Ghana Poverty Reduction-GPRS I and Growth and Poverty Reduction Strategy - GPRSII), the Millennium Development Goals (MDGs) and the Ghana Shared Growth and Development Agenda (GSGDA) demonstrate various governments' intentions to reduce the economic burden of disease, among others, with a particular focus on morbidity, mortality and child malnutrition (Van Den Boom, Nsowah - Nuamah \& Overbosch, 2008). These have culminated in health sector reforms which have largely sought to establish systems that coordinate resources to reduce and eventually eliminate the conditions of extreme poverty and social deprivation.

While the objective of health reforms is to improve the overall performance of the health sector by increasing the quality of life in Ghana (Ministry of Health, 1996), previous attempts at improving the health sector have however been described as unduly focused on crises management and implementation of pre-packaged projects and programmes (Attipoe, 2001). It is therefore not surprising that studies on health care seeking behaviour amplify how severe reductions in government expenditure on health care, coupled with the introduction of user fees create problems such as inaccessibility and inequality in health care utilisation (Asenso-Okyere, Anum, Osei-Akoto \& Adukonu, 1998). These studies re/echo long standing concerns associated with health care in Ghana such as the limited access to health facilities as population growth outstrips the provision of social services; limited financial access due to the high cost of disease prevention and treatment and poor quality of health services as a result of frequent shortages of personnel, drugs and other supplies (Gyimah, Baffour \& Addai, 2006). These bottlenecks continue to hinder progress on health care delivery and the achievement of the goals of various initiatives of governments (Ministry of Health, 1996). Today, the cost of ill health is a major concern to poor households as it exposes their vulnerabilities and takes a toll on their already low incomes (Wagstaff \& van Doorslaer, 2003).

The challenge of effective and equitable health delivery is further compounded by multiple costs. For instance, fees and charges have been shown to keep dozens of rural dwellers from hospital-based treatment (Bennett, Mills \& Gibson, 2007). Even when formal fees are low or nonexistent, there may be informal fees or other costs that pose significant barriers to health care utilization by the poor. These include costs of transportation, medication and food (Gertler \& Van der Gaag, 1988). Even appropriate or decent clothing can be a challenge to the very poor. However, the unpredictability of costs of health care suggests that up-front payment of user-fees hinder access to health care utilisation since unaffordable out-of-pocket payments could be high enough to cause financial catastrophe and impoverishment especially during severe ailments or major injuries $(\mathrm{Xu}, 2005)$. It is within this context that this paper examines the real cost of treating malaria under the health 
insurance scheme of Ghana with the view to advancing knowledge regarding the drivers of health seeking behaviour among policy holders of the National Health Insurance Scheme (NHIS).

\section{Contextual and Conceptual Review}

This section explores the evolution and operational elements of the health insurance scheme in Ghana ending with a conceptual framework that explains the dimensions and consequences of the costs of illness.

\section{The National Health Insurance Scheme in Ghana}

Before member countries of the World Health Organization (WHO) endorsed a resolution on sustainable health financing, universal coverage and social health insurance in 2005 , the government of Ghana, as part of its poverty reduction programme, had already laid the foundation for a NHIS (Donnell, Van Doorslaer, Wagstaff \& Lindelow, 2008). The National Health Insurance Act (Act 650) was enacted in 2003 to allow for the concurrent existence of district-wide (public) mutual health insurance schemes, private mutual health insurance schemes and private commercial health insurance schemes. Noteworthy is that each district is required to have at least one mutual health insurance scheme on condition that it has up to 2000 members and receives financial support from the NHIS to deliver pro-poor services. The defined benefit package under the scheme includes inpatient hospital care, outpatient care at primary and secondary levels and, emergency and transfer services even though district schemes are empowered to exercise their independent discretion to determine additional benefits they could provide.

The National Health Insurance Authority (NHIA) is the national governing body of the NHIS. At the district level, each mutual health insurance scheme is managed by a board elected by a body which has representatives from Community Health Insurance Committees (CHICs). CHIC members represent geographically determined 'Health Insurance Communities' (HICs) within each district. These committees officially oversee the collection of contributions within specific individual HICs, supervise the transfer of deposits into the District Health Insurance Fund (DHIF), and represent community interests in managing the mutual health insurance scheme.

In terms of financing, the NHIS is essentially woven into the country's tax regime. The largest proportion of finance to the scheme is through indirect taxes on selected goods and services, that is the value added tax (VAT). The NHIS Act, 2003 (Act 650) charges a 2.5\% VAT levy on selected goods and services in the country. Other sources of financing the scheme include the collection of $2.5 \%$ of workers contribution to the Social Security and National Insurance Trust (SSNIT) which is deducted at source as their contributions to the scheme while non-SNNIT contributors are levied via direct premium payment through membership registration. This means that all SSNIT contributors are exempted from paying the premium upfront but nonetheless, they are required to register in order 
to benefit from the scheme. On the other hand, informal sector workers pay a premium based on their income level, which is determined by the CHIC. The lowest-income group is expected to pay a premium of about GH\$7.20 or US\$8 while those in the highest income group pay $\mathrm{GH} \$ 48.00$ or US\$53.2. In reality, however, most districts charge a flat premium (GH\$7.2O) per annum due to problems involved in categorizing people into different socioeconomic groups (Osei - Akoto \& Adamba, 2011).

The Health Insurance Act further establishes that unless alternative private health insurance schemes demonstrate sufficient credibility, it is mandatory for every Ghanaian to belong to the national scheme (Government of Ghana, 2003). However, in practice, membership is optional for non-formal sector workers who represent the bulk of the country's population. Meanwhile, attempts have been made to allocate a proportion of funds mobilized as an 'exemption fund' to be channeled through district implementing bodies to cater for the poor and vulnerable groups (core poor or indigent) as defined under the Law. In 2008, the Scheme also started exempting pregnant women on condition that they attended ante natal clinics or delivered their babies safely in health facilities accredited by the NHIA.

\section{The Cost of Illness Approach}

The framework informing this analysis is the Cost of Illness Approach (CIA). Studies on the magnitude of direct and indirect costs of health care and their relative impacts on households is inconclusive (Russell, 2001). A case study of malaria in Rwanda which compared the ratios of direct and indirect costs revealed that indirect costs were 3.6 times greater than direct costs (Ettling \& Shepard, 1991). Generally, studies that combine both direct and indirect costs of illness in order to computed the total economic effect on households revealed that costs normally exceeded $10 \%$ of household income. For instance, the total household cost of malaria per year was $18 \%$ of annual income in Kenya, $13 \%$ in Nigeria (Leighton \& Foster, 1993) and nearly 19 percent in the Amazon region of Brazil (Sawyer, 1993). Furthermore, household expenditure on health care shows that low income households in Malawi spent $32 \%$ of their annual income on direct and indirect costs associated with the treatment of malaria compared to $4.2 \%$ in more wealthy households (Ettling, McFarland, Schultz \& Chitsulo, 1994). In Ghana, Asenso-Okyere and Dzator (1997) found that indirect costs, which included transport and unproductive days, represented $79 \%$ of total costs of each malaria episode. Despite this trend, these studies have not shown how people cope with the cost burden.

The CIA framework suggests that costs that surpass the household's daily or monthly budget may trigger coping strategies such as borrowing or asset sales. When households are vulnerable to poverty and struggle to meet daily food and fuel needs, the loss of daily earnings due to illness or treatment expenses trigger the search of alternative coping strategies. Such strategies may include relying on social networks or organizations that offer credit thereby highlighting the debilitating effects of illness on household asset 
portfolio (Russell, 1996). The figure below illustrates the Cost of Illness framework adopted for the study.

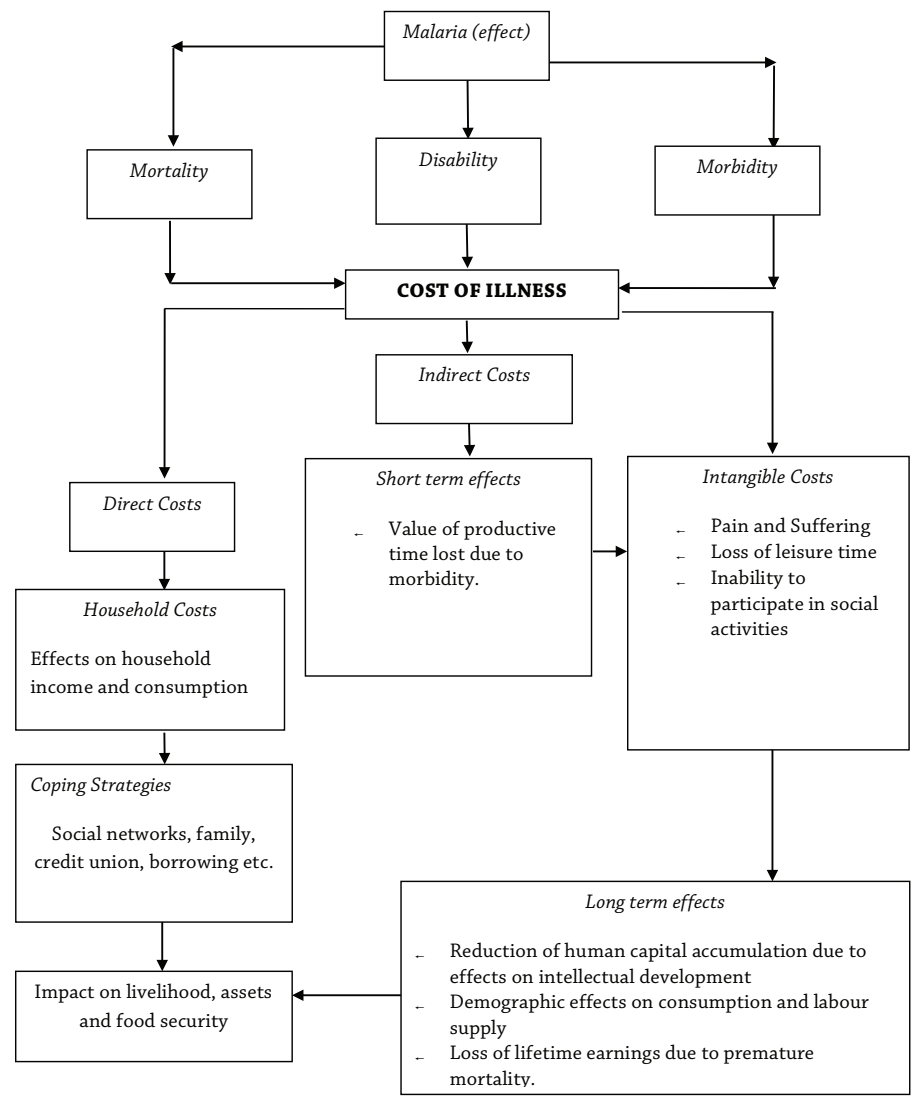

Figure 1: Conceptual Framework for the Cost of Illness Approach.

Source: Asenso Okyere et al. (2009) with some modifications

\section{Data and Method of Analysis}

\section{Design}

The field study entailed the adoption a cross-sectional observational cost-of-illness survey design for malaria treatment using the prevalence approach (Hodgson, 1994). It involved estimating the explicit and implicit costs for a particular population. Data were collected from individuals in sampled households whose responses were retrospective, as they referred to only one episode of malaria in the last three months. We used a multi- 
stage sampling procedure to select our research participants. The first process involved the selection of one community each from three clusters, each representing a given geographical area (urban, peri-urban and rural). Given the district-wide nature of the NHIs and based on the demarcation of the district into 'HICs,' Savelugu, a relatively urban community, Diare, a peri-urban town and Zieng, a rural community, were selected for the study. A list of valid health insurance card users from the selected communities who were diagnosed with malaria in the last three months was obtained from the health facilities in the District. This was used to compile the sample frame. A sample size of 200 individuals was then selected systematically.

\section{Statistical analysis}

In line with the CIA, direct cost was computed as:

$\mathrm{TDC}_{\mathrm{d}}=\mathrm{MC}_{\mathrm{d}}+\mathrm{NMC}_{\mathrm{d}}$; Where $\mathrm{TDC}_{\mathrm{d}}=$ Total Direct Cost, $\mathrm{MC}_{\mathrm{d}}=$ Direct Medical Cost and $\mathrm{NMC} C_{\mathrm{d}}=$ Direct Non Medical Costs.

But $M C_{d}=d_{1}+d_{2}+d_{3}+d_{4}+d_{5}$ and $N M C_{d}=d_{6}+d_{7}$

Given that:

$d_{1}=$ fees for registration at health facilities; $d_{2}=$ consultation fees; $d_{3}=$ cost of medicine; $d_{4}=$ cost of injection; $d_{5}=$ laboratory tests; $d_{6}=$ cost of transportation incurred by patient and caretaker; $d_{7}$ = any other direct costs incurred in the process of seeking health care for malaria.

The computation of Total Direct Costs is given as TDC $=d_{1}+d_{2}+d_{3}+d_{4}+d_{5}+d_{6}+d_{7}$.

Indirect costs on the other hand are the resources forgone as a result of a health condition (Haddix \& Shaffer, 1996). The indirect cost was estimated using the Human Capital Approach (Asante \& Asenso-Okyere, 2003). This approach estimates the indirect costs associated with illness and premature death in terms of forgone income. Within this framework, opportunity costs of work or loss of productivity are treated as labour earnings that are forgone as a result of adverse health outcomes resulting from illness or time spent to receive treatment.

The analysis considered the ages of respondents and the productive time they lost due to malaria in an attempt to impute the market value of time lost. Because real labour earnings are mostly inconsistent with legislated minimum wages, and tend to vary widely in developing economies due to market failures, the daily wages paid to casual farm labourers was used to value productive time lost to individuals. This was considered more appropriate in a predominantly agrarian District where the residents were mostly farmers. The amount of time spent by patients and caregivers to receive treatment for malaria, and the number of workdays lost due to the disease was computed based on the local wage (daily agricultural wage) payable to casual farm labour. Different wages paid to adults and children between 10-18 years were duly considered. 
To Asante and Asenso-Okyere (2003), indirect cost per episode can be computed as $Y=\mu\left(\nu_{1}+\right.$ $\nu_{2}+\gamma_{3}+\gamma_{4}+\gamma_{5}$ ). Where $\gamma_{1}=$ travel time to obtain health care; $\gamma_{2}=$ time spent in health facility to receive treatment; $v_{3}=$ time spent caring for patient; $v_{4}=$ time loss due to illness/length of sickness; $\nu_{5}=$ other indirect costs due to illness; and $\mu=$ local wage rate.

\section{Results and Discussion}

\section{Direct Cost}

The study did not find any evidence of monetary payments made by respondents for registration, consultation, injection, laboratory tests and prescribed medicines in health facilities in the District. Apparently, the health insurance scheme guarantees that valid card holders receive care for malaria treatment in line with the provisions defined in the Scheme's benefit package. To ensure that health insurance clients adequately obtain drugs prescribed for them in the health facilities, the DMHIS has accredited some selected licensed pharmacy shops in Savelugu and Tamale to dispense medications on the NHIS approved drug list. However, two plausible reasons could explain why some respondents incurred direct medical expenditures. Firstly, some NHIS beneficiaries may have purchased medications that were not included in the NHIS approved list of drugs while others had to pay for transportation even though we do not have evidence to suggest that "under the counter" expenses were incurred in the course of receiving treatment at the facilities.

An average direct medical bill paid to a health facility was about GH\$O.85 (USD 0.55 ). This represents $3.6 \%$ of total direct cost of treatment, while direct non-medical cost constituted $96.4 \%$. All direct non-medical costs incurred by respondents and their caretakers were in the form of transportation to health facilities. Cost of transportation was lowest for residents in Savelugu, the district capital. Direct cost made up of only $1.2 \%$ of the total cost of malaria treatment in the health facilities. The low direct medical cost suggests that patients who attended hospitals to treat malaria were considerably insulated from monetary payments.

\section{Indirect Cost}

In the Savelugu-Nanton District, about 13 hours (a little more than half a day) was lost to each patient due to malaria morbidity. The average travel time to a health facility was 22 minutes. The study revealed that the average travel time was higher for respondents in Diare because a considerable proportion of residents attended the Savelugu Hospital. About $79.7 \%$ of total treatment time was spent to wait for various services such as registration, consultation, injection, laboratory tests and medication in health facilities. Respondents also averagely waited for about 16 minutes in the facilities before health workers attended to them. They further indicated that waiting time for all patients was worse on particular days designated for antenatal care due to high hospital attendance. 
The mean time spent on registration was 12.7 minutes in Savelugu, 9.5 minutes in Diare and 8.7 minutes in Zeing. Time-use on registration was highest in Savelugu, probably due to overcrowding at the District hospital. Furthermore, an average time of 16.4 minutes was spent on consultation in Savelugu compared to 18.3 minutes in the three communities combined. It was observed that the shortest time patients and their caretakers waited in health facilities were during inoculation. Averagely, it took less than a minute to receive an injection (o.44 minutes) in the Health Centres.

It is important to note that the severity of an episode of malaria had ripple effects on households as some members had to temporarily stop their productive activities to cater for their sick kin. Caretakers, on average, spent about 1.4 days with malaria patients. Children below 10 years were more likely to have caretakers $(58 \%)$ compared to adults ( 32.5 $\%)$. More than half of caregivers (74.2\%) were informal sector workers. McIntyre, Muirhead and Gilson (2002) argued that morbidity that kept household heads and breadwinners from work weakened the financial fortunes and livelihood security of poor families. The opportunity costs resulting from respondent's inability to work was observed and presented in Table 1, which shows the distributional effects of malaria on respondent's daily activities in the study communities.

Table 1: Effect of sickness on economically active patient's daily activities

\begin{tabular}{|l|l|l|l|}
\hline Locality & N (200) & Stopped work & Continued with work \\
\hline Savelugu & 106 & 55.9 & 48.8 \\
\hline Diare & 64 & 24.6 & 42.7 \\
\hline Zeing & 30 & 19.5 & 8.5 \\
\hline
\end{tabular}

Source of Data: Field Survey (2009).

\section{Value of time spent on malaria treatment under health insurance.}

The indirect cost of malaria treatment was disproportionately greater than direct costs under the health insurance scheme. The share of indirect cost was $98.8 \%$ of the total cost of malaria treatment by national health insurance beneficiaries. Imputed travel time was valued at GH\$1.3 (US\$ 0.84) per household while the estimated value of time spent to wait in health facilities averaged GH\$ 5.1 (USD 3.30) in forgone earnings. However, health insurance card holders did not generally feel that beneficiaries under the scheme waited too long in the course of seeking health care as compared to non-insured clients. It is therefore not surprising to observe that hordes of patients that throng the district hospital from far and near communities accounted for the spectacle of long queues characteristic of the district hospital.

Despite the relevance of increased access to health services due to the utilisation of NHIS, the achievement of the intended outcomes of the scheme appeared to be constrained by 
inadequate doctors in the District, resulting in the delays and long queues at the District Hospital. The monetary value of time loss due to registration was GHфo.63 (US\$ 0.41) and GH $\$ 1.5$ (US\$ 0.96) for laboratory processes. The cumulative value of time spent on receiving medication was estimated at $\mathrm{GH} \$ 0.87$ (US\$0.57) per head. The value of work days lost by caretakers was $26 \%$ of total indirect cost borne by households. The indirect value of casual work days lost to patients alone was estimated at GH\$45.8 (US\$29.7) on average. This suggests that the amount of wages forgone by patients and their caretakers per day GH\$64.2 (US\$41.6) could have been saved if the disease had not attacked their households.

Table 2: Cost of treating an episode of malaria

\begin{tabular}{|l|l|}
\hline Cost component & Cost (US\$) \\
\hline Average direct Cost & 0.55 \\
\hline Average indirect cost & 45.7 \\
\hline Average total cost & 46.2 \\
\hline
\end{tabular}

Source: Field Survey (2009).

The study showed a drastic reduction in the cost of health care compared to earlier studies such as that by Asante and Asenso-Okyere (2003). It is however not surprising since this study was conducted within the prevailing NHIS regime while many similar studies were carried out under the previous full cost recovery regime.

\section{Drivers of Health Seeking Behaviour}

The benefit package defined under the NHIS presupposes that merely possessing a valid health insurance card could guarantee free access to health care in all accredited public and private health facilities. The underlying incentives that promote enrolment into the scheme are nonetheless quite varied as indicated in the table below.

Table 3: Reasons for enrolling into the NHIS

\begin{tabular}{|l|l|l|l|l|}
\hline Reasons & Savelugu & Diare & Zeing & Total \\
\hline Healthcare affordable & 46.2 & 54.7 & 46.6 & 49.0 \\
\hline Health security & 16.0 & 4.7 & 13.3 & 12.0 \\
\hline Incentive to access healthcare & 17.9 & 17.2 & 16.7 & 17.5 \\
\hline Not covered by exemption & 1.9 & 1.6 & 6.7 & 2.5 \\
\hline Confidence in the system & 17.9 & 21.0 & 16.7 & 19.0 \\
\hline Total & 53.0 & 32.0 & 15.0 & 100.0 \\
\hline
\end{tabular}

Source: Field Survey (2009). 
Prior to the introduction of the NHIS, popular attitudes of respondents corroborated with earlier findings that highlighted self-medication and delays in seeking care (Asenso - Okyere, Anum, Osei-Akoto \& Adukonu, 1998). Findings from this study show that a considerable number of people in the District, about $54.5 \%$ are still likely to undertake self-medication as a preliminary measure in times of ill health compared to $26.5 \%$ who would visit a hospital without insurance. About $15 \%$ are also more likely to take herbal medication to cure malaria as a first choice of treatment option. Failure to get cured after such initial attempts would normally induce patients to consider other alternative modes of treatment. Under such circumstances, patients tend to disprove both self-medication and herbal medicine as those alternatives become unattractive partly due to the lack of professional supervision and tendency of the disease to become even more severe at this stage.

It was therefore not surprising that more than three quarters $(85.5 \%)$ of the respondents sought treatment from either a hospital or clinic after unsuccessfully attempting selfmedication. The overwhelming preference for institutionalized care is thus a reflection of the public's reliance on hospital based care as supported by the statistical test on the treatment options respondents preferred in their first and second attempts to treat malaria $\left({ }^{2}=38.799,=0.000\right)$. Further variations were observed in health seeking behaviour as well. Whereas the choice of self-medication for instance decreased by $50.5 \%$ as a second mode of seeking treatment, herbal medication only dipped by $5.5 \%$ while the choice of hospital based care surged by $59 \%$. It was also observed that none of the respondents who preferred herbal medication as a first remedial attempt to treat malaria opted for unorthodox health care in their second attempt to treat malaria. Figure 2 presents the factors that influence health care seeking behaviour under the DMHIS in the SaveluguNanton District.

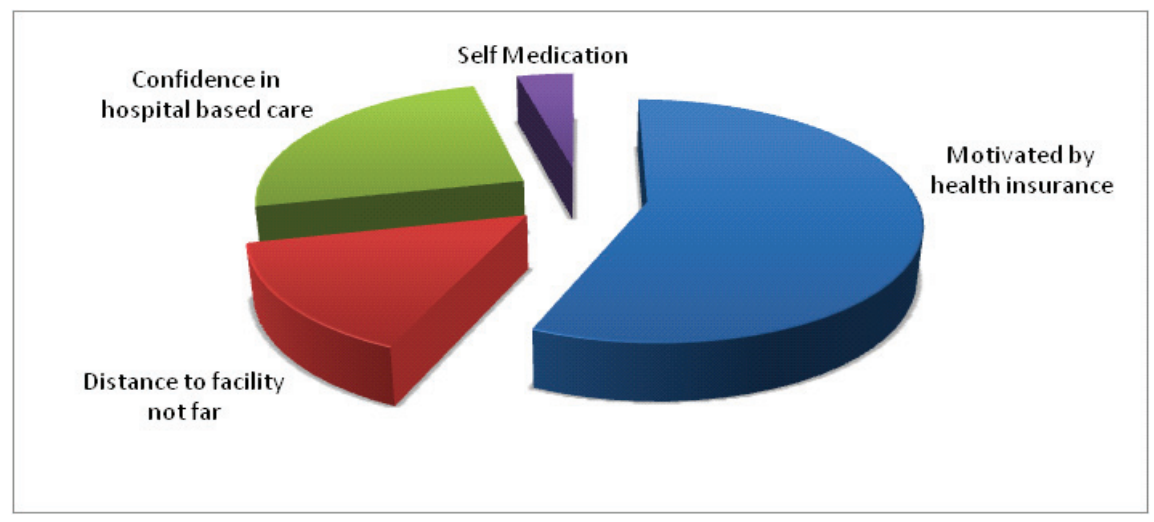

Figure 2: Factors that influence health care seeking behaviour.

Source of Data: Field Survey (2009). 
While enumerating reasons for immediately visiting a health facility, more than half of the study population $(56.5 \%)$ claimed they were motivated by the NHIS while $15 \%$ who hesitated before attending a health facility felt constrained by distance to the nearest facility. It is worth noting that the incentive to report a disease or ailment to a health facility is neither sex nor location specific as there was no form of association between these variables ( $>0.05$ ).

\section{Policy Discussion and Conclusion}

The NHIS is largely viewed as an alternative financing mechanism rather than a compulsory all-encompassing system. The operation of health insurance is also an essential health promotion tool that is based on the principles of social capital. The possession of health insurance enables respondents to visit health facilities without hesitation unlike in the previous 'cash and carry' regime that was characterized by delays in attending health facilities. Even though majority of research participants were first time health insurance users, the most stimulating factors that drove them to register under the scheme included, among other things, the need to afford health care, enjoy health security and to have guaranteed access to health care. The direct and indirect costs were GHф0.85 (USDo.55) and GHф70.5 (USD45.7) respectively. Most indirect costs were incurred when both patients and their caretakers lost productive days due to malaria.

Therefore, it can be concluded that the benefits derived from the NHIS were crucial in defining health seeking behavior, promoting access to health care and improving the health conditions of subscribers. Despite the usefulness of health insurance to beneficiaries, there are still challenges that need to be addressed in order to improve health service delivery in Ghana. We noted that households affected by malaria attach little importance to the indirect costs of seeking health care. This has important implications for the economic welfare of households as income loss resulting from productive time spent due to malaria could have been invested to earn some income and probably contribute to household welfare.

In order to situate the development challenges in the study areas in a proper context more generally and costs of illness more specifically, we argue that costs of health care must be re-examined in ways that recognize the opportunity costs incurred by households while consuming health care. Since the opportunity cost of work tends to increase as a result of ill health and time loss, interventions such as increasing the allocation of medical personnel to the District, which appears to be malarious, could considerably reduce the amount of time lost to patients and their caretakers. We also recommend the use of the "mobile clinic model" in the District as this could reduce the need to travel from remote localities to the only District hospital in Savelugu for health care.

Finally, the widespread nature of poverty, characterized by low incomes, in the study area could potentially inhibit large households' affordability of full coverage for all members. This can be due the adoption of selective cover and underinsurance in large households, 
which could potentially increase health inequality or promote fraud as uninsured household members tend to use cards belonging to valid card holders to seek treatment. This perverse coping strategy will undoubtedly drain the scheme if the free riding is encouraged due to the income dynamics of poor communities. Thus, since majority of people are found in the informal sector, it would be imperative to introduce flexible prepayment arrangements that allow payment by installments for non-SNNIT contributors as this would facilitate health for all prospective users of health insurance irrespective of their income.

\section{References}

Asante, F. A \& Asenso-Okyere K. (2003). Economic Burden of Malaria in Ghana. A Technical Report Submitted to the World Health Organisation (WHO), African Regional Office (AFRO), Ghana(unpublished).

Asenso-Okyere, K. \& Dzator, J. A. (1997). Household Cost of seeking Malaria Care: A retrospective study of two districts in Ghana. Social Science and Medicine, 45, pp. 659667.

Asenso-Okyere, K.; Anum, A.; Osei-Akoto, I. \& Adukonu, A. (1998). Cost Recovery in Ghana: Are there any changes in Health Seeking Behaviour? Health Policy and Planning, 13, pp. 181-188.

Asenso-Okyere, K.; Asante, F.A.; Tarekegn, J. \& Andam, S. K. (2009). The Linkages between Agriculture and Malaria: Issues of Policy, Research and Capacity Strengthening. (Discussion Paper No. oo86). International Food Policy Research Institute (IFPRI).

Attipoe, D. K. (2001). Public Health in Ghana. Public Health Medicine 3(2), pp. 72-77.

Bennett, S.; Mills, A. \& Gibson, L. (Eds.) (2007). Health Economic Development and Household Poverty. Routledge Publishers.

Donnell, O.; Van Doorslaer, E.; Wagstaff, A. \& Lindelow, M. (2008). Analyzing Health Equity using Household Survey Data: A Guide to Techniques and their Implementation. WBI Development Studies: The World Bank. Washington DC

Ettling, M. B. \& Shepard, D. S. (1991). Economic cost of malaria in Rwanda. Tropical Medicine and Parasitology, 42 (3): 214-218.

Ettling, M.; McFarland, D. A.; Schultz, L. J. \& Chitsulo, L. (1994). Economic impact of Malaria in Malawian households. Tropical Medical Parasitology, 45, 74-79. 
Gertler, P. J. \& Van der Gaag, P. (1988). Measuring the willingness to pay for services in Developing Countries. Living Standards Measurements Study (LSMS) Working Papers No. 45. Washington DC: World Bank.

Government of Ghana (1996). Health Sector - Five Year Programme of Work. Accra, Ghana: Ministry of Health.

Government of Ghana (2003). The National Health Insurance Act, 2003. Accra, Ghana: National Health Insurance Authority.

Gyimah, S.0.; Takyi, B. K. \& Addai, I. (2006). Challenges to the reproductive-health needs of African women: On religion and maternal health utilization in Ghana. Social Science and Medicine, 62 (12): 2930-2944.

Haddix, A. C \& Shaffer, P. A. (1996). Cost-Effectiveness Analysis. In: Haddix, A. C., Teutsch, S. M., Shaffer, P. A \& Duñet, D. O (Eds). Prevention Effectiveness: A Guide to Decision Analysis and Economic Evaluation. New York: Oxford University Press.

Hodgson, T. A (1994). Cost of illness in Cost-Effectiveness Analysis. A Review of the Methodology. Pharmacoeconomics, 6 (6): 536-552

Leighton, C \& Foster, R. (1993). Economic impacts of malaria in Kenya and Nigeria. Bethesda, MD: Abt Associates. U.S. Health Financing and Sustainability Project, 6. Maryland, USA

Lucas, H \& Nuwagaba, A. (1999). Household Coping Strategies in Response to the Introduction of User Charges for Social Services: A Case Study on Health in Uganda. Brighton, United Kingdom: Institute of Development Studies. Working Paper No. 86.

McIntyre, D.; Muirhead, D. \& Gilson, L. (2002). Geographic patterns of deprivation in South Africa: informing health equity analysis and public resource allocation strategies. Health Policy and Planning, 17: 30-39.

Onwujekwe, O., Chima, R \& Okonkow, P. (2000). Economic burden of malaria illness on households versus that of all other illness episodes: A study in five malaria holoendemic communities. Health Policy 54, 143-159

Osei-Akoto, I. \& Adamba, c. (2011). Pseudo-Tax-Based Insurance for Health Care and Iatrogenic Poverty in Ghana. Institute of Statistical, Social and Economic Research (ISSER), University of Ghana.

Russell, S. (1996). Ability to pay for health Care: Concepts and Evidence. Health Policy Planning 11:219-237.

Russell, s. (2001). Can households afford to be ill? : The role of the health system, material resources and social networks in Sri Lanka. PhD Thesis, London School of Hygiene and Tropical Medicine, University of London, United Kingdom (unpublished). 
Sawyer, D. (1993). Economic and social consequences of malaria in new colonization projects in Brazil. Social Science Medicine, 37 (9)" 1131-1136.

Van Den Boom, Nsowah - Nsowah \& Overbosch (2008). Health - Care Provision and Self Medication in Ghana. In Aryeetey E. \& Kanbur R. (Eds.). The Economy of Ghana: Analytical Perspectives on Stability, Growth and Poverty. Woeli Publishing Services.

Wagstaff, A \& van Doorslaer, E. (2003). Catastrophe and Impoverishment in paying for Health Care in Vietnam. Journal of Epidemiology and Community Health, 57(9): 644645 .

Xu K. (2005). Designing Health Financing Systems to reduce Catastrophic Expenditure. Technical briefs for Policy Makers No. 2. World Health Organization, Geneva. 